\title{
Aversão à desigualdade e preferências por redistri- buição: A percepção de mobilidade econômica as afeta no Brasil?
}

\author{
Yasmín Salazar Méndez \\ Professora - Faculdade de Ciências - Escuela Politécnica Nacional \\ Endereço: Ladrón de Guevara E1 1.253 - Edificio de Administración, $7^{\circ}$ piso, Quito - Equador \\ P.O Box 17-01-2759 - E-mail: yasmin.salazar@epn.edu.ec
}

\begin{abstract}
Fábio D. Waltenberg
Professor - Centro de Estudos sobre Desigualdade e Desenvolvimento - Universidade Federal Fluminense - Endereço: Rua Prof. Marcos Waldemar de Freitas Reis, $\mathrm{s} / \mathrm{n}^{\circ}$ - Bloco F - Campus do Gragoatá - Niterói/RJ - CEP: 24210-201 - E-mail: waltenberg@economia.uff.b

Recebido em 21 de dezembro de 2014. Aceito em 06 de setembro de 2015.
\end{abstract}

\section{Resumo}

A noção de que a redistribuição é dos ricos para os pobres permitiria concluir a priori que os pobres são os principais partidários de medidas redistributivas, ao serem os potenciais beneficiários. Não obstante, estudos realizados principalmente para países desenvolvidos sugerem que a aversão à desigualdade e as preferências por redistribuição são moldadas por fatores que vão além do pecuniário. Neste trabalho, analisa-se o efeito da mobilidade econômica subjetiva na aversão à desigualdade e na demanda por redistribuição dos brasileiros, usando-se uma base de dados única, representativa do país, coletada em 2012. Os resultados sugerem que, em contradição com previsões teóricas e com evidências de países desenvolvidos, mesmo pessoas que aspiram ascender socialmente no futuro incomodam-se com a desigualdade e são favoráveis a políticas redistributivas. Brasileiros que perceberam uma piora na sua situação econômica também mostram-se favoráveis à redistribuição, resultado mais convencional. Ambos os conjuntos de resultados são confirmados por estimações feitas em subamostras definidas por renda familiar. Levantam-se hipóteses para se tentar explicar os resultados inesperados.

\section{Palavras-Chave}

Aversão à desigualdade. Preferências por redistribuição. Expectativas de mobilidade futura.

\footnotetext{
- Os autores gostariam de agradecer a Juliana Londoño, Erik Figueiredo, Danielle Carusi, e aos participantes de seminários internos do NEE/CEDE/UFF e do seminário Ipea 435 - 2013, por importantes críticas, comentários e recomendações feitos a versões anteriores deste trabalho, bem como pareceristas e editoria deste periódico. Agradecemos também a Lena Lavinas pelo convite para participar no projeto "Medindo o Grau de Aversão à Desigualdade da População Brasileira Através dos Resultados do Bolsa-Família", que permitiu a obtenção da base de dados deste trabalho. Yasmín Salazar Méndez é grata, ainda, à CAPES pelo apoio financeiro concedido via programa "PEC-PG". A responsabilidade por esta versão final cabe exclusivamente aos autores.
} 


\begin{abstract}
The notion that redistribution is from the rich to the poor a priori could lead to the conclusion that the poor are the main supporters of redistributive policies, since they are the potential beneficiaries. Nevertheless, evidence for developed countries suggests that inequality aversion and preferences for redistribution are shaped by factors beyond pecuniary concerns. This paper analyzes the effect of subjective economic mobility on inequality aversion and on the demand for redistribution, employing a unique dataset collected in 2012, which is representative of the Brazilian population. In contrast with theoretical predictions and empirical evidence for developed countries, results suggest that even people who aspire to ascend socially in the future dislike inequality and support redistributive policies. Individuals who perceived a decline in their social situation have also shown support for redistribution, which is a more standard result. Both sets of results are confirmed by estimations undertaken on subsamples defined according to family income. Some hypotheses are raised attempting to explain the unexpected results.
\end{abstract}

\title{
Keywords
}

Inequality aversion. Preferences for redistribution. Prospects of future mobility.

\section{JEL Classification}

D31. D63. H30.

\section{Introdução}

A noção de que a redistribuição é dos ricos para os pobres nos faria supor a priori que os mais pobres seriam os mais descontentes com a distribuição de renda vigente, bem como os principais partidários de medidas redistributivas, por serem seus potenciais beneficiários. Essa ideia, formalizada por Meltzer e Richard (1981), autores do modelo seminal das preferências por redistribuição, tem sido desafiada com recentes modelos econômicos teóricos e evidência empírica que apontam limitações dos modelos mais simples, ou até mesmo do próprio paradigma do homo economicus, para explicar as preferências por redistribuição e propõem a incorporação de fatores além do pecuniário.

Entre os inúmeros fatores analisados na literatura, cabe mencionar: crenças acerca do papel da sorte e do esforço (Bénabou e Tirole, 2006; Piketty, 1995), religião (Stegmueller et al. 2011; Scheve e Stavasage, 2006), "preferências sociais", isto é, preocupações não estritamente individualistas (Fong, 2001; Alesina et al. 2001; Luttmer, 2001) e características pessoais como sexo, idade ou estado conjugal (Pittau et al. 2013; Alesina e Giuliano, 2011; Linos e West, 2003). 
A compreensão da influência de tais fatores na formação das atitudes redistributivas permitiria uma melhor articulação de aspectos econômicos relacionados com o estado de bem-estar e a redistribuição (Fong 2001), pois o fato de os formuladores de políticas não levarem em conta as aspirações e percepções da população poderia dar origem a atitudes resistentes até mesmo a políticas sociais bem concebidas e bem executadas. Em função de uma falta de conhecimento, por parte dos governantes, do que pensam seus governados a respeito das razões para a pobreza ou das percepções que têm sobre a eficácia de políticas sociais, parte da população poderia, por exemplo, mostrar-se hostil e insensível com relação aos seus membros mais desfavorecidos, ou poderia avaliar certas políticas supostamente equalizadoras como "ineficazes ou injustas" (Bowles e Gintis, 2001, p. 1; tradução própria) ainda que, tecnicamente, fossem impecáveis ou ao menos tão boas quanto possível. O estudo do tema também possibilitaria um melhor entendimento das diferenças no tamanho dos governos (exemplo: Estados Unidos versus países da Europa), assim como de diferenças, entre países, de alocações do gasto social entre distintas rubricas do welfare state (intra-Europa, por exemplo) ou entre modalidades de política social (por exemplo, universais versus focalizadas).

A mobilidade - social ou econômica - também aparece como um dos fatores mais estudados. A influência da mobilidade social foi sugerida já há muito tempo pelo cientista político De Tocqueville (1835), que poderia ser considerado o motivador das pesquisas mais recentes. $\mathrm{O}$ autor sugeria que as diferenças entre estadunidenses e europeus provinham das diferentes percepções de mobilidade. Aqueles teriam uma maior expectativa (acertada ou não) de mobilidade ascendente, razão pela qual apoiariam níveis menores de redistribuição do que estes. Na ciência econômica, consideram-se Hirschman e Rothschild (1973) os pioneiros em modelar a influência das percepções de mobilidade social, com seu "efeito túnel", que explicaria a satisfação que experimentam os indivíduos ao observarem experiências de mobilidade de pessoas próximas. A satisfação explica-se, entre outras razões, pela esperança de que eles próprios viessem a experimentar melhoria econômica e social. As experiências de mobilidade passadas foram incorporadas por Piketty (1995) na sua "teoria do aprendizado racional", na qual considera que o histórico de mobilidade econômica influencia na formação das crenças sobre o esforço e a sorte - aqueles que, a partir das observações de 
experiências próprias e de seus próximos, terminam por aderir a um pensamento meritocrático seriam menos favoráveis à redistribuição.

Finalmente, Bénabou e Ok (2001), com seu denominado modelo "POUM" (Prospect of Upward Mobility, ou expectativa de mobilidade ascendente) mostram a importância das expectativas de mobilidade social. Apesar de serem potenciais beneficiárias de políticas redistributivas, pessoas pobres mostrariam baixos níveis de apoio à redistribuição sempre que alimentassem expectativas de mobilidade futura ascendente. Assim, as preferências individuais seriam moldadas pelo histórico de vida e por inferências sobre o futuro, e não dependeriam unicamente da situação atual.

A maioria dos trabalhos de preferências por redistribuição analisa os casos dos Estados Unidos e da Europa. Gaviria (2007) e Silva e Figueiredo (2013) estudaram o papel da mobilidade social na América Latina. No primeiro trabalho analisa-se o apoio à economia de mercado - observa-se que é mais forte entre aqueles que têm percepções de mobilidade passada ascendente e que esperam mobilidade futura- e às privatizações - os resultados mostram que as pessoas com percepções negativas de mobilidade seriam menos favoráveis à privatização-. No caso de Silva e Figueiredo (2013) os achados sugerem que mesmo pessoas que esperam melhoria da situação dos filhos no futuro apoiariam políticas redistributivas, resultado em desacordo, tanto com os observados em países desenvolvidos, como com as previsões teóricas.

Pouco se conhece sobre o efeito da mobilidade na aversão à desigualdade e na demanda por redistribuição no Brasil. Não obstante, há estudos que abordam mobilidade econômica e social no país (apresentados na seção 2.1) e apontam para um ambiente relativamente dinâmico em termos de mobilidade em décadas recentes. Isto sugere que é relevante analisar sua influência nas preferências por redistribuição, visando a uma melhor compreensão dos padrões de comportamento que poderiam guiar as decisões políticas dos brasileiros.

A inesperada eclosão da "Revolução dos 20 centavos", em junho de 2013, num momento em que o Brasil encontrava-se sob os olhares do mundo pelo relativo sucesso na redução da desigualdade e da pobreza, pelo crescimento econômico da década anterior, e pela ascensão da assim chamada "nova classe média", sugere a urgência de diálogo 
e entendimento das demandas reais da população, assim como a atualização dos temas que devem ocupar os lugares prioritários da agenda social.

Desta forma, este trabalho procura, em primeiro lugar, obter elementos iniciais de resposta a questões como: o nível de desigualdade atual é um aspecto que incomoda ou existe uma tendência a aceitar o status quo? Os brasileiros em geral apoiam medidas redistributivas? Em termos concretos, em que medida são favoráveis à progressividade de impostos? E qual é o papel exercido pela mobilidade econômica subjetiva na determinação dessas posições normativas? Há trabalhos que analisam o impacto da mobilidade de rendimentos na desigualdade, não obstante, ainda não se estudou de modo adequado o efeito da mobilidade de renda nas preferências redistributivas dos brasileiros.

Este procura preencher essa lacuna. Para cumprir esses objetivos, analisa-se neste artigo o efeito da mobilidade econômica intergeracional - em termos das percepções de mobilidade passada e das expectativas de mobilidade futura - na determinação do nível de aversão à distribuição de renda vigente e das preferências por redistribuição no Brasil, com dados provenientes de um survey conduzido nacionalmente em 2012. Este artigo também pretende gerar frutos indiretos, ao instigar e nortear a realização de mais estudos sobre o Brasil, tanto empíricos - possivelmente com outras bases de dados como teóricos, por meio da elaboração de modelos mais completos e mais adaptados à realidade brasileira e latino-americana, de modo a poder conciliar melhor teoria e resultados observados.

O trabalho está organizado da seguinte forma: a seção 2 contém uma revisão da literatura teórica e empírica, e algumas informações referentes à mobilidade social e econômica no Brasil. Na seção 3 são apresentados os dados e a metodologia. $\mathrm{Na}$ seção 4 , apresentam-se e discutem-se os principais resultados obtidos. Finaliza-se o artigo na seção 5 , com as conclusões, as quais abordam implicações dos resultados, bem como limitações deste estudo. 


\section{Literatura sobre mobilidade e preferências por redistribuição}

\subsection{Mobilidade: conceitos e situação no Brasil}

A mobilidade social e econômica tem tido um papel de destaque em análises políticas e econômicas, desde De Tocqueville (1835), que abordou a mobilidade social como fator decisivo para entender as diferenças políticas entre estadunidenses e europeus, até a vinculação da mobilidade com a desigualdade sugerida por Friedman (1962), na forma de uma correlação negativa entre os dois fenômenos.

A mobilidade tem múltiplas facetas e sua interpretação depende da perspectiva dos pesquisadores (Fields e Ok, 1999; Fields, 2004), sendo isto uma fonte de confusão frequente. Por isso, é necessário revisar alguns conceitos básicos de mobilidade econômica, foco deste trabalho. Primeiro, a mobilidade pode ser intergeracional (comparação da situação econômica de pais e filhos) ou intrageracional (comparação, em ao menos dois momentos de tempo, de indivíduos ou famílias). Segundo, os indicadores utilizados são variados - educação, renda, ocupação etc. - bem como as unidades de análise - indivíduos, trabalhadores, famílias etc. -, ampliando o leque de possibilidades de estudo. Terceiro, o nível - agregado ou microeconômico - também constitui uma diferença entre os estudos de mobilidade. Por fim, distinguem-se ao menos seis diferentes conceitos de mobilidade econômica: a) dependência temporal, b) movimento de participação, c) fluxo de renda, d) mudança direcional dos rendimentos, e) mobilidade como fator equalizador de renda no longo prazo, e f) movimento de posição. ${ }^{1}$

Um aspecto também destacado pelos autores é o uso indistinto de "mobilidade social" e "mobilidade econômica", apesar de não serem sinônimos. Grosso modo, a sociologia estuda a mobilidade social entendida como variações de classe e ocupação influenciadas pelas transformações tecnológicas e econômicas, enquanto o foco de economistas está nas mudanças em indicadores de bem-estar ou econômicos observados em momentos distintos de tempo (Ferreira $e t$ al., 2013). Em termos de mobilidade econômica no Brasil, Ferreira e Veloso (2006) encontraram evidências de mobilidade intergeracional de rendimentos, sendo maior na região Sudeste e entre pessoas de

1 Fields (2004) e Ferreira et al. (2013) apresentam a definição dos diferentes conceitos de mobilidade. 
cor/raça negra. O efeito positivo da mobilidade de renda na desigualdade é confirmado por Nascimento e Souza (2005), Figueiredo e Ziegelman (2009) e Antigo e Machado (2013). Apesar do impacto positivo da mobilidade na desigualdade, inspirado em Abatemarco (2004), Figueiredo (2009) questiona se tal fenômeno é, necessariamente, um fato socialmente desejável, uma vez que pode introduzir um elemento de incerteza aos agentes. Sua análise sugere que ambos os efeitos, positivos e negativos, estão relacionados com a mobilidade de renda. Quanto maior for a aversão à desigualdade de uma sociedade, e quanto menor for o nível de aversão ao risco, mais benéficos serão os efeitos da mobilidade econômica. No tocante à mobilidade social intergeracional, observou-se no Brasil uma movimentação intensa desde o início do século XX, cuja maior parcela corresponde à mobilidade ascendente de curta distância (Pastore e Silva, 2000). ${ }^{2}$ Com dados da Pesquisa Nacional por Amostra de Domicílios Contínua (PNAD), os autores concluíram que, entre 1973 e 1996, houve uma variação na mobilidade total de 4,7 pontos percentuais (de $58,5 \%$ a $63,2 \%$ ). A mobilidade estrutural (relacionada com mudanças no mercado de trabalho) no mesmo período reduziu-se de $32,8 \%$ a $31,4 \%$, e a mobilidade circular (para uma pessoa ascender, outra deve ocupar sua posição) foi de $25,7 \%$ a $31,8 \%$. Como conclusão, pode-se dizer que pareceu existir uma movimentação de classes, com alguma modificação de posições econômicas.

Ribeiro (2007), usando os mesmos dados, aponta que, em 1973, $64 \%$ dos homens estavam em uma posição social diferente da que ocuparam seus pais. Em 1982, esse valor aumentou para $71 \%$ e se manteve sem alterações em 1996. O autor atribui estas mudanças à diminuição da imobilidade no setor rural, especialmente entre 1973 e 1982, quando houve um forte êxodo rural. Para esse autor, apesar de a mobilidade social total ter aumentado, não houve aumento na mobilidade ascendente, constatando que o aumento da mobilidade total se deveu à queda da mobilidade ascendente e ao acréscimo na mobilidade descendente. Em 1973, 85\% da mobilidade total foi ascendente e, em 1996, esse valor foi de $80 \%$. Desagregando por sexos, Ribeiro (2012) sugere uma movimentação, especialmente nas mulheres. A mobilidade total para homens em 1973 foi de 55,3\% e de $67,3 \mathrm{em} 2008$. No caso das mulheres a mobilidade total em 1973 foi de $57,5 \%$ e em 2008 de $75,4 \%$.

2 Mobilidade caracterizada por muitas pessoas ascendendo pouco e poucas pessoas ascendendo muito (Pastore e Silva, 2004). 
As percepções de mobilidade social foram analisadas em um estudo feito nas comunidades do Rio de Janeiro em 1961. Observou-se que $50 \%$ dos entrevistados perceberam que sua situação piorou e 30\% consideraram que nada mudara, porém, ao serem indagados sobre a percepção do impacto em outras pessoas (amigos, parentes ou outros brasileiros em geral) a maioria se pronunciou positivamente (Bonilla, 1961 apud Hirschman e Rothschild, 1973). ${ }^{3}$ Para Pero (2006), o Rio de Janeiro tem a mobilidade social mais alta do país e a posição social não depende tão intensamente da origem social. Em 1996, 80\% das pessoas empregadas estavam em estratos diferentes dos ocupados por seus pais. Não obstante, se comparado com outros estados, o Rio de Janeiro revelava, no período em questão, uma diminuição na mobilidade ascendente, o que "(...) pode mexer na autoestima das pessoas, com reflexos sobre comportamentos políticos e eleitorais, movimentos sociais e religiosos, violência, entre outros" (Ibid, p. 152).

\subsection{Aversão à desigualdade, preferências por redistribuição e mobili- dade: aspectos teóricos}

De Tocqueville (1835) referiu-se às diferenças nos comportamentos redistributivos dos europeus e dos estadunidenses, que seriam moldados por percepções diferentes de mobilidade social, os últimos seriam mais otimistas com respeito ao futuro e menos favoráveis a políticas redistributivas. Mais de um século depois, o argumento de De Tocqueville foi retomado, gerando contribuições teóricas e empíricas de economistas.

As percepções de mobilidade social foram introduzidas na ciência econômica pelos pioneiros Hirschman e Rothschild (1973). Os autores fazem uso de uma analogia para explicar o bem-estar individual como um túnel com duas pistas $A$ e $B$ (no mesmo sentido) e que registra trânsito intenso. Os veículos da pista $A$ começam a se movimentar enquanto que os da pista $B$ permanecem no mesmo lugar. Baseados na experiência positiva de $A$, os indivíduos de $B$ confiam em que também haverá movimentação na sua pista, experimentando - ao menos inicialmente - sentimentos de contentamento. Esse

3 Hirschman e Rothschild (1973) relatam esses resultados como uma constatação do efeito túnel. 
fenômeno, conhecido como "efeito túnel", em termos econômicos se traduz como a satisfação (inicial) que sentem indivíduos pelo sucesso dos outros, colocando de lado sentimentos inclusive tão fortes quanto a inveja. É importante salientar que isso acontece não como reflexo de bondade ou altruísmo, e sim porque os indivíduos são capazes de sentir empatia e ter a esperança de também alcançar no futuro um sucesso semelhante ao observado. O reverso da moeda, porém, consiste na raiva e na indignação que acometem os indivíduos, após certo tempo, caso não observem melhorias efetivas de vida para si mesmos, ao contrário do que observam à sua volta.

A parte positiva do efeito ocorreria desde que observadas certas condições, a saber: i) sociedade ser composta majoritariamente por indivíduos capazes de experimentarem empatia; ii) haver homogeneidade social (língua, religião, etnia); iii) arranjos familiares serem tradicionais e haver fortes laços familiares; iv) ser prevalente a concepção de que o sucesso é associado à sorte. Pode-se acrescentar, como fator implícito, um grau razoável de otimismo que permita acreditar que dias melhores estejam por vir. Como nem todas essas condições se verificam em todos os países em todos os momentos, o "efeito túnel" seria uma explicação razoável à questão de por que algumas sociedades são mais tolerantes com a desigualdade do que outras.

Já Piketty (1995) argumenta que a mobilidade social e econômica tem repercussões tanto no nível individual (que se refletem nas preferências políticas) quanto no coletivo (resultados políticos agregados). Analisando as preferências políticas de eleitores com origens sociais diferentes, mas que na atualidade têm uma posição econômica similar, mostra que o aspecto pecuniário não é fator decisivo para uma postura política e redistributiva, e que esta se forma através de um processo de aprendizagem das experiências de mobilidade passada, com a exposição dos indivíduos a informações e ideias que moldam suas crenças sobre o papel do esforço e da sorte como mecanismo de sucesso econômico e social. Para explicar esse processo de aprendizagem individual, propõe o que denomina "teoria do aprendizado racional", que formaliza por que os indivíduos têm diferentes níveis de apoio à redistribuição, justificando que isso não se deve à maximização de funções-objetivo diferentes, mas ao impacto das experiências de mobilidade passada. 
Finalmente, a proposta que poderia ser considerada a mais contraintuitiva é de Bénabou e Ok (2001), que analisam o fato de que os pobres de hoje poderiam não apoiar medidas redistributivas no futuro dado que esperam ascender economicamente (eles próprios e/ou seus filhos). Através da denominada hipótese "POUM", os autores formalizam a ideia de que os indivíduos que na atualidade têm uma renda abaixo da média esperam no futuro ser mais ricos do que a média. Para isto assumem que: i) a política fiscal e as medidas redistributivas têm uma duração de longo prazo, ii) os agentes não são muito avessos ao risco, e iii) a renda esperada no futuro é função crescente e côncava da renda atual. ${ }^{4}$ No modelo, consideram um processo, cujo estado de equilíbrio de redistribuição tem três quartos da população como apoiadores de medidas redistributivas correntes, enquanto, no período subsequente, dois terços dessa porção esperam uma renda acima da média, momento em que se prevê que se mostrem contrários a qualquer política redistributiva. Com o intuito de testar a validez de seu modelo teórico e mostrando uma visível preocupação com sua "aparente natureza paradoxal" (Bénabou e Ok, 2006, p. 474) realizou-se exercício empírico com dados do PSID (Panel Study on Income Dynamics). ${ }^{5} \mathrm{O}$ efeito POUM foi corroborado, mas existem ressalvas à generalização da hipótese para outros países. Para isto, os autores recomendaram a realização de estudos usando dados diferentes e de melhor qualidade, assim como a incorporação de medidas objetivas e subjetivas.

\subsection{Evidência empírica}

Alguns trabalhos empíricos foram desenvolvidos com o intuito de analisar o efeito da mobilidade social e, em menor escala, a mobilidade econômica, na determinação da aversão à desigualdade e das preferências individuais por redistribuição. Em geral, usam-se modelos de variáveis dependentes limitadas (probit ou logit, binários ou ordenados). Uma dificuldade para realizar estudos relacionados com mobilidade é a escassez de bases de dados longitudinais, que permitiriam acompanhar a trajetória social e econômica de um indivíduo

${ }^{4}$ Indivíduos com renda abaixo da média serão contra medidas redistributivas no futuro se e somente se a renda esperada no futuro for função crescente e côncava da renda atual.

5 Survey que vem sendo realizado nos Estados Unidos desde 1968, contém uma amostra representativa nacional de 18000 indivíduos distribuídos em 5 mil famílias. São abordados temas relacionados com: emprego, renda, riqueza, consumo, saúde, educação etc. 
ou de sua família. No caso específico de se desejar testar a hipótese POUM, seria necessário conhecer a renda individual atual, o grau de aversão ao risco, as expectativas de mobilidade futura, assim como as expectativas de duração das políticas redistributivas. Esses dados não costumam estar disponíveis.

Em termos de mobilidade de renda, destacam-se Alesina e La Ferrara (2005), que usam proxies de mobilidade de renda intergeracional (nível de educação e da ocupação de pais e filhos) e percepções subjetivas de mobilidade passada e futura para analisar o caso estadunidense; e Corneo e Grüner (2002), que analisam países da Europa e os Estados Unidos, utilizando como proxy de mobilidade ascendente intergeracional uma pergunta que compara a situação do respondente com a situação dos pais ( "mais rico que os pais"). Ambos os estudos sugerem o efeito significativo das proxies de mobilidade utilizadas. Quem considera que está numa situação econômica melhor com relação a seus pais, os que têm uma ocupação com maior prestígio se comparada com a ocupação dos progenitores, e os que mantêm expectativas futuras de mobilidade seriam opostos a políticas redistributivas. Em Alesina e La Ferrara (2005), a variável que relaciona o nível de educação entre pais e filhos é significativa e positiva, e duas explicações são oferecidas pelos autores. Primeiro, se existe uma grande brecha entre os níveis educacionais de pais e filhos, significa que houve uma melhora no nível educativo dos filhos, esse sinal positivo explicaria um alto apoio à redistribuição de pessoas com origem socioeconômica desfavorecida. ${ }^{6}$

No que tange à mobilidade social, Ravaillon e Lokshin (2000) analisaram o efeito túnel na década de 1990 para a Rússia, corroborando esse paradigma. Com auxílio da economia experimental, Checchi e Filippin (2004) acharam evidências que sustentam a validez da hipótese POUM para o caso italiano, assim como Cojocaru (2014) corroborou-a para um grupo de países pertencentes à União Europeia.

A evidência empírica disponível para a América Latina não a confirma. Silva e Figueiredo (2013) suspeitam que uma das premissas básicas da POUM, que faz referência ao horizonte temporal das políticas redistributivas, poderia não ser cumprida quando os agentes não têm expectativas de políticas redistributivas de longa duração e

6 Assume-se uma correlação positiva entre renda e capital humano (Alesina e La Ferrara, 2005). 
quando o horizonte temporal considerado para fazer suas inferências é menor do que o proposto pela POUM.

Em geral, observa-se interesse crescente pelo estudo das preferências por redistribuição da América Latina, já tendo sido investigados os seguintes fatores: desigualdade de renda (Cramer e Kaufman, 2001) percepções individuais de distribuição de renda (Cruces et al. 2013 sobre a Argentina), mobilidade social (Silva e Figueiredo, 2013; Gaviria, 2007; sobre a América Latina; Londoño, 2011 sobre a Colômbia); apoio a políticas universais com ênfase na chamada renda básica de cidadania e no Brasil (Waltenberg, 2013). Apesar do impacto da mobilidade de renda na desigualdade, a influência deste aspecto na demanda por redistribuição não foi analisada na América Latina.

\section{Dados e metodologia}

\subsection{Dados}

Este trabalho utiliza uma base única, ainda pouco explorada. Os dados foram obtidos através do survey "Medindo o Grau de Aversão à Desigualdade da População Brasileira Através dos Resultados do Bolsa-Família" realizado em 2012 (Ver no Anexo 1 detalhes da pesquisa). Para tal efeito, foram entrevistadas 2.200 pessoas com 16 anos ou mais de idade. A entrevista consistiu na aplicação de um questionário estruturado de 54 perguntas fechadas e com variáveis que proporcionaram informação sobre atitudes relacionadas com o apoio a medidas redistributivas e programas sociais; opiniões sobre pobreza, desigualdade, justiça social, mobilidade social; variáveis demográficas; entre outras. As entrevistas foram aplicadas nas áreas urbana e rural; os resultados têm representatividade nacional.

\subsection{Estratégia empírica}

A estratégia empírica adotada para se analisar o efeito das percepções de mobilidade econômica nas preferências individuais por redistribuição no Brasil baseia-se no pressuposto de que o apoio a políticas 
redistributivas ${ }^{7}$ é uma variável latente subjacente $\mathrm{Y}^{*}$, que pode ser modelada da seguinte forma:

$$
\mathrm{Y}^{*}=\mathrm{I} \beta+\mathrm{J} \zeta+\mathrm{A} \theta+\mathrm{R} \eta+\mathrm{G} \delta+\mathrm{M} \gamma+\varepsilon
$$

onde I é um vetor de características individuais (tais como sexo, estado conjugal, idade, cor, educação); J é um vetor de percepções de justiça social (causas da pobreza); A é um vetor de variáveis que expressam o autointeresse (renda familiar etc.); $\mathrm{R}$ é um vetor de variáveis associadas com a religião (religioso ou não etc.), $\mathrm{G}$ é um vetor de variáveis geográficas (regiões brasileiras), $M$ é um vetor de medidas de mobilidade (percepções de mobilidade passada e expectativas de mobilidade futura); e $\varepsilon$ é o termo de erro. As estimações são realizadas com modelos logit.

A variável Y* não é observável. Não obstante $Y_{i} \in\{0,1\}$, sendo 1 o valor que indica que um indivíduo apoia políticas redistributivas, assim:

$$
Y_{i}=\left\{\begin{array}{c}
1 \text { se } Y_{i}^{*}>0 \\
0 \text { em caso contrário }
\end{array}\right.
$$

Parte-se da hipótese de que, apesar da possibilidade de vínculo entre as preferências por redistribuição, que se manifestam nas preferências eleitorais -que, por sua vez, no médio prazo, afetariam as probabilidades de efetiva mobilidade social, ascendente ou descendente-, não se identifica o verdadeiro efeito da redistribuição nas percepções de mobilidade passada e futura, dado que essa melhoria poderia vir por diversas vias, ${ }^{8}$ e, caso existisse um viés, este não teria o mesmo efeito em todos os grupos da população (Alesina e La Ferrara, 2005).

7 O mesmo raciocínio descrito neste parágrafo acerca de "preferências por redistribuição" também vale para "aversão à desigualdade". Na seção 3.3, discutem-se esses conceitos e suas inter-relações.

8 Entre 1993 e 2004 os seguintes fatores contribuíram para a redução da desigualdade de renda no Brasil: redução nos retornos médios da educação, diminuição das diferenças entre as áreas urbanas e rurais, programas de transferência de renda do governo, e redução da desigualdade entre grupos raciais (Ferreira et al. 2006). Analisando o período $1995-2004$ Soares (2006) concluiu que programas de transferência de renda do governo, como o Bolsa Família, são responsáveis por um quarto da queda desigualdade, e os três quartos restantes se devem aos rendimentos do trabalho. Mais recentemente, Brito et al. (2015) analisaram o efeito global da política de valorização do salario mínimo no Brasil no período 1995 - 2013, atribuindo-lhe um impacto global estimado de $72 \%$. 


\subsection{Variáveis dependentes}

As variáveis dependentes foram escolhidas de forma que permitissem inferir a postura do entrevistado frente a questões distributivas e redistributivas. As dificuldades inerentes à tarefa de se tentar medir adequadamente a demanda por redistribuição de um indivíduo são múltiplas e notórias. Em primeiro lugar, não é fácil sintetizar o conceito que se deseja mensurar numa única questão ou mesmo num conjunto de questões. Em segundo lugar, mesmo que fosse possível se chegar a uma boa tradução do conceito em questões, restaria o problema de como medir adequadamente, uma vez que não há uma escala natural para se mensurar e expressar tal conceito.

Uma terceira fonte de dificuldades é a eventual dissonância entre o que os indivíduos realmente pensam e o que declaram pensar. Por exemplo, por convenções sociais vigentes, pode ser considerado ofensivo defender abertamente um status quo de desigualdade ou mesmo um aumento da desigualdade. Por fim, pode haver um hiato entre a demanda por redistribuição quando se trata de escolhas estruturadas em torno a princípios abstratos gerais, sem custos evidentes para o respondente (ex. "deve haver mais redistribuição no país?") da efetiva disposição a redistribuir em escolhas mais concretas e potencialmente custosas (ex. "você estaria disposto a pagar mais impostos a fim de aumentar a redistribuição?").

Diante dessas dificuldades, a literatura tem agido de formas variadas. Via de regra, a opção pelo uso de uma questão, ou conjunto de questões, como proxy para a demanda por redistribuição é definida pelas variáveis disponíveis na base de dados que se tem em mãos. Neste artigo, optamos por realizar cinco estimações diferentes, baseadas em quatro variáveis dependentes de naturezas diferentes aversão à desigualdade, demanda por redistribuição em situações abstratas (duas versões) e numa situação concreta, ainda que somente indiretamente relacionada a um eventual trade-off -, bem como em uma variável composta a partir das quatro variáveis dependentes simples.

$\mathrm{Na}$ Tabela 1 é apresentada a percentagem de respostas obtidas em cada uma das opções das diferentes perguntas. 
Tabela 1 - Perguntas selecionadas como variáveis dependentes e porcentagem de $\operatorname{respostas}^{1}$

\begin{tabular}{|c|c|c|c|}
\hline Conceito investigado & \multicolumn{1}{|c|}{ Questão } & \multicolumn{2}{|c|}{ Resposta } \\
\cline { 2 - 4 } Aversão à desigualdade & $\begin{array}{c}\text { R1: A distribuição de renda no país ainda } \\
\text { é muito preocupante }\end{array}$ & $20 \%$ & $80 \%$ \\
\hline $\begin{array}{c}\text { Demanda por redistribuição, em nível } \\
\text { abstrato e sem custos evidentes }\end{array}$ & $\begin{array}{c}\text { R2: No Brasil existem algumas pessoas } \\
\text { muito ricas e outras muito pobres. Isto é } \\
\text { um problema a ser combatido }\end{array}$ & $29 \%$ & $71 \%$ \\
\hline $\begin{array}{c}\text { Demanda por redistribuição, em nível } \\
\text { um pouco mais concreto (posiciona- } \\
\text { mento frente a política específica) }\end{array}$ & $\begin{array}{c}\text { R3: O governo deve intervir para reduzir } \\
\text { as desigualdades entre ricos e pobres } \\
\text { uma porção maior de sua renda em im- } \\
\text { postos do que as pessoas com rendas } \\
\text { mais baixas. }\end{array}$ & $19 \%$ & $81 \%$ \\
\hline $\begin{array}{c}\text { R5: Variável que combina respostas das } \\
\text { quatro anteriores }\end{array}$ & $27 \%$ & $69 \%$ \\
\hline
\end{tabular}

Fonte: Survey "Medindo o Grau de Aversão à Desigualdade da População Brasileira Através dos Resultados do Bolsa-Família" (2012).

Elaboração própria.

1 O questionário original contempla possibilidades de resposta que vão de 1 a 5 . Neste trabalho as respostas foram adaptadas a uma escala binária: o valor de 1 corresponde às respostas de $4 \mathrm{e}$ 5 ; e o valor de 0 corresponde às respostas de 1,2 , e 3 . Esta decisão segue prática da literatura.

2 R5 é o somatório das variáveis dependentes R1, R2, R3 e R4, sua escala varia entre 0 e 4.

A primeira questão capta a ideia de aversão à desigualdade percebida. O status quo é rejeitado por quatro quintos dos entrevistados. As duas questões seguintes captam a ocorrência, ou não, de demanda por redistribuição, num plano abstrato ou de princípios, sem custos envolvidos. Uma ampla maioria (81\%) considera que o governo deve reduzir as desigualdades entre ricos e pobres. Em concordância com essa opinião, $71 \%$ consideram que o fato de existirem no Brasil pessoas muito ricas e outras muito pobres é um problema a ser combatido. Ao responder a essas questões, o indivíduo revela seu desejo de que medidas sejam tomadas para modificar o status quo.

Quanto à quarta questão, 69\% dos indivíduos revelam-se favoráveis a uma tributação progressiva. Trata-se de uma pergunta um pouco mais concreta, pois faz referência a uma política específica, contudo, só chegaria a implicar um trade-off de fato em condições muito específicas. ${ }^{9}$ É preciso reconhecer que não é a questão ideal para se testar

9 A questão implicaria a imposição de um trade-off: (i) para os indivíduos mais ricos (hoje ou no futuro), em quem recairiam os custos de uma eventual reforma tributária que caminhasse 
o que se poderia denominar "disposição a distribuir", mas não há questão que cumpra esta função adequadamente na base de dados. ${ }^{10}$

Por fim, construiu-se uma variável composta a partir das quatro questões anteriores. Combinar respostas a diferentes perguntas em uma variável dependente composta é uma prática comum na literatura. Por exemplo, Fong (2001) utiliza seis perguntas da Gallup Poll Social Audit Survey, e a variável dependente de sua análise é o somatório das respostas, enquanto Tóth e Keller (2014) constroem um índice de apoio à redistribuição obtido com uma análise de componentes principais. Tentou-se construir uma variável dependente a partir de técnicas de análise de componente principal, contudo, ela não apresentou a confiabilidade necessária. ${ }^{11}$ Restou-nos, portanto, a opção de construir uma variável dependente composta pela soma às respostas das quatro perguntas já discutidas. Dadas as altas percentagens favoráveis à redistribuição nas perguntas que integram a variável composta, não é surpresa que esta também apresente uma maioria de $73 \%$ que seria favorável à redistribuição. Esta variável oferece uma visão geral da redistribuição, considerando alguns aspectos inerentes a este conceito já mencionados antes: aversão à desigualdade e demanda por redistribuição em níveis abstrato e relativamente concreto.

\subsection{Variáveis de mobilidade econômica e de controle}

Construíram-se dois índices para captar a mobilidade econômica subjetiva dos entrevistados, conforme o modelo seguido por Graham e Pettinato (2000): 1) Índice de expectativas de mobilidade ascendente (POUM) e, 2) Índice de percepção de mobilidade (IPM). O cálculo de tais índices foi feito com a seguinte formulação:

no sentido de mais progressividades dos impostos; (ii) contanto que tais indivíduos tivessem uma clara percepção de que são (ou virão a ser) os mais ricos, o que não necessariamente ocorre (cf. Rocha e Urani, 2007); (iii) contanto que os mais ricos considerassem que o sistema atual não é progressivo.

${ }^{10}$ A fim de tentar abordar trade-offs, pensamos na possibilidade de utilizar uma variável dependente que expressa uma escolha que envolve custos e benefícios (mais impostos e mais recursos para saúde, ou menos impostos e menos recursos para saúde), porém, a redação da questão era bastante tortuosa e poderia dar margem a diversas interpretações diferentes aos entrevistados, ao contrário, acreditamos, das quatro questões que finalmente foram usadas neste artigo.

${ }^{11}$ A análise da correlação existente entre as variáveis com o teste de Kaiser-Meyer-Olkin revelou um valor de 0,56 , considerado como "miserable" na escala do teste referido. 


$$
\text { POUM }=0.75 * \text { POUMS }+0.25 * \text { POUML }
$$

Onde POUMS é a expectativa de mobilidade social do entrevistado em um horizonte de 5 anos (curto prazo), e POUML é a expectativa de mobilidade social que o entrevistado tem de seus filhos, quando estes tiverem sua idade (longo prazo).

$$
I P M=0.75 * I P M S+0.25 * I P M L
$$

Onde IPMS é a percepção de mobilidade social passada do entrevistado em um horizonte de 5 anos (curto prazo), e IPML é a percepção de mobilidade passada do entrevistado comparando sua situação atual com a de seus pais, quando tinham a mesma idade do entrevistado (longo prazo).

A justificativa para se colocar um peso maior no componente de curto prazo baseia-se no fato de que as experiências próprias poderiam modelar as atitudes de uma pessoa com uma base mais real (pois são acontecimentos que o indivíduo efetivamente experimentou ou espera experimentar) e não expectativas do que irá acontecer com seus filhos ou do que aconteceu com seus pais (Piketty, 1995; Graham e Pettinato, 2000).

A escala do IPM e do POUM está em um intervalo compreendido entre 1 e 5. No que se refere ao IPM, só 6\% avaliaram com a máxima pontuação (5), ou seja, manifestaram que melhorou muito sua posição econômica se comparada com a de seus pais e deles mesmo há cinco anos. (Ver Figura 1). Nas expectativas de mobilidade futura, na mesma escala, $18 \%$ dos entrevistados revelam-se otimistas com respeito ao seu futuro e o de seus filhos. (Ver Figura 2).

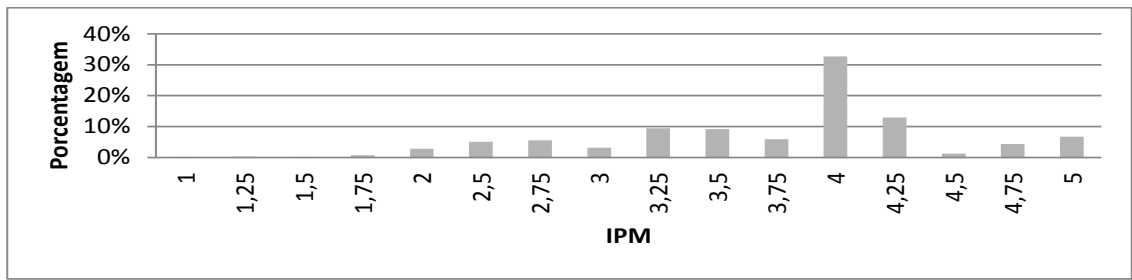

Figura 1 - Percepções de mobilidade passada IPM

Fonte: Survey "Medindo o Grau de Aversão à Desigualdade da População Brasileira Através dos Resultados do Bolsa-Família" (2012).

Elaboração própria. 


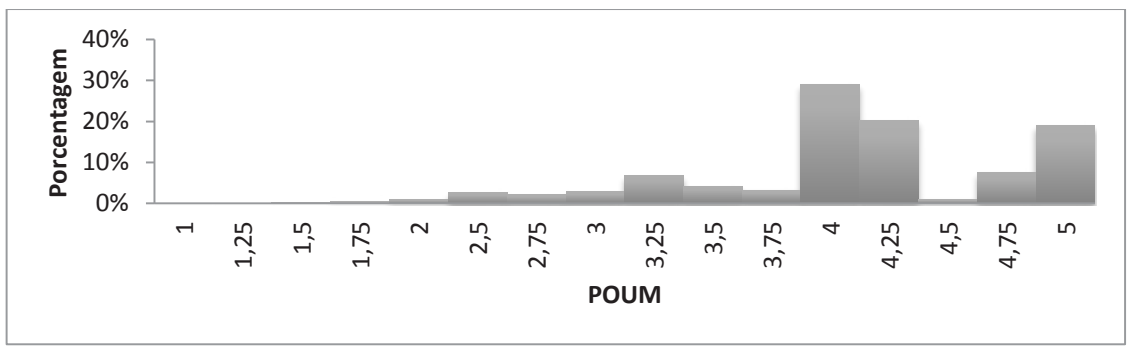

Figura 2 - Expectativas de mobilidade futura POUM

Fonte: Survey "Medindo o Grau de Aversão à Desigualdade da População Brasileira Através dos Resultados do Bolsa-Família" (2012).

Elaboração própria.

Os indivíduos com as menores rendas familiares são mais cautos com respeito ao seu futuro, visto que a maioria das observações têm um POUM entre 3 e 4 pontos (Figura 3). Nas outras categorias observase uma maior confiança no futuro. Os entrevistados manifestaram que esperam uma situação muito melhor tanto para eles como para seus filhos. O grupo dos mais otimistas ostenta os maiores níveis de renda.

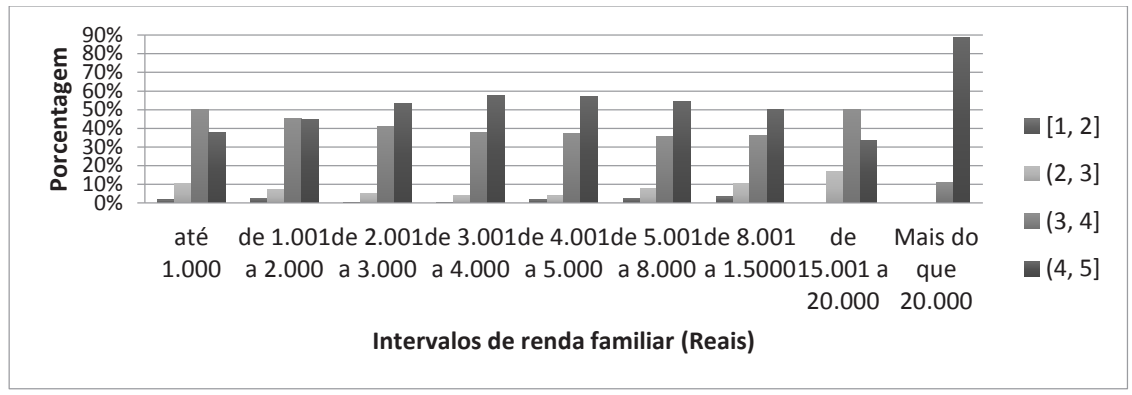

Figura 3 - POUM observado por grupos de renda familiar.

Fonte: Survey Grau de aversão à desigualdade (2012).

Elaboração própria.

Finaliza-se esta seção com as estatísticas descritivas e a descrição de cada variável na Tabela 2 . 
Tabela 2 Estatísticas descritivas variáveis independentes

\begin{tabular}{|c|c|c|c|c|c|}
\hline Variável & Descrição da variável & Média & $\begin{array}{l}\text { Desvio } \\
\text { padrão }\end{array}$ & Mínimo & Máximo \\
\hline Idade & Idade em anos do entrevistado & 38,81 & 15,58 & 16 & 90 \\
\hline Idade ao Quadrado & Variável Idade ao quadrado & 1748,95 & 1373,35 & 256 & 8100 \\
\hline Mulher & Sexo feminino & 0,51 & 0,50 & 0 & 1 \\
\hline Casado $^{3}$ & $\begin{array}{l}\text { Pessoas casadas, que moram com um } \\
\text { companheiro ou que têm uma união estável. }\end{array}$ & 0,48 & 0,50 & 0 & 1 \\
\hline Branco $^{4}$ & Pessoas que autodeclaram ser de cor branca & 0,39 & 0,49 & 0 & 1 \\
\hline Superior $^{5}$ & $\begin{array}{l}\text { Pessoas com ensino superior completo (graduação } \\
\text { e pós-graduação) como formação mais elevada. }\end{array}$ & 0,15 & 0,35 & 0 & 1 \\
\hline Formal $^{6}$ & Empregados com carteira de trabalho assinada & 0,42 & 0,49 & 0 & 1 \\
\hline Informal & Empregados sem carteira de trabalho assinada & 0,11 & 0,31 & 0 & 1 \\
\hline $\begin{array}{l}\text { Não pertence à } \\
\text { força laboral }\end{array}$ & $\begin{array}{l}\text { População não economicamente ativa } \\
\text { (inclui estudantes, aposentados e donas de casa). }\end{array}$ & 0,24 & 0,43 & 0 & 1 \\
\hline $1001<$ Renda $<2000^{7}$ & $\begin{array}{l}\text { Pessoas com renda familiar mensal entre } \\
R \$ 1.001 \text { e } R \$ 2.000\end{array}$ & 0,31 & 0,46 & 0 & 1 \\
\hline $2001<$ Renda $<3000$ & $\begin{array}{l}\text { Pessoas com renda familiar mensal entre } \\
\mathrm{R} \$ 2.001 \text { e } \mathrm{R} \$ 3.000\end{array}$ & 0,17 & 0,38 & 0 & 1 \\
\hline $3001<$ Renda $<5000$ & $\begin{array}{l}\text { Pessoas com renda familiar mensal entre } \\
\mathrm{R} \$ 3.001 \text { e } \mathrm{R} \$ 5.000\end{array}$ & 0,17 & 0,37 & 0 & 1 \\
\hline Renda $>5000$ & $\begin{array}{l}\text { Pessoas com renda familiar mensal maior do } \\
\text { que } R \$ 5.000\end{array}$ & 0,10 & 0,31 & 0 & 1 \\
\hline Falta de oportunidades ${ }^{8}$ & $\begin{array}{l}\text { Pessoas que consideram a falta de oportunidades } \\
\text { a principal causa da pobreza. }\end{array}$ & 0,37 & 0,48 & 0 & 1 \\
\hline Esforço\&Oportunidade & $\begin{array}{l}\text { Pessoas que consideram a falta de oportunidades } \\
\text { e a falta de esforço principal como as causas para } \\
\text { a pobreza. }\end{array}$ & 0,26 & 0,44 & 0 & 1 \\
\hline POUM & $\begin{array}{l}\text { Expectativas de mobilidade social (do entrevistado } \\
\text { próprio e dos filhos). }\end{array}$ & 4,09 & 0,71 & 1 & 5 \\
\hline IPM & $\begin{array}{l}\text { Percepções de mobilidade passada(do entrevistado } \\
\text { próprio e com respeito à situação dos pais) }\end{array}$ & 3,74 & 0,74 & 1 & 5 \\
\hline Religiosos ${ }^{9}$ & $\begin{array}{l}\text { Pessoas que autodeclaram pertencer a uma } \\
\text { religião }\end{array}$ & 0,98 & 0,13 & 0 & 1 \\
\hline Praticantes ${ }^{10}$ & Pessoas que manifestam ter uma vida religiosa ativa & 0,45 & 0,50 & 0 & 1 \\
\hline Sudeste ${ }^{11}$ & $\begin{array}{l}\text { Entrevistados que moram em uma cidade da } \\
\text { região Sudeste. }\end{array}$ & 0,23 & 0,42 & 0 & 1 \\
\hline Norte & $\begin{array}{l}\text { Entrevistados que moram em uma cidade da } \\
\text { região Norte }\end{array}$ & 0,17 & 0,38 & 0 & 1 \\
\hline Nordeste & $\begin{array}{l}\text { Entrevistados que moram em uma cidade da } \\
\text { região Nordeste. }\end{array}$ & 0,26 & 0,44 & 0 & 1 \\
\hline Centro-Oeste & $\begin{array}{l}\text { Entrevistados que moram em uma cidade } \\
\text { da região Centro-Oeste. }\end{array}$ & 0,16 & 0,36 & 0 & 1 \\
\hline
\end{tabular}

Número de observações: 1830

Fonte: Survey "Medindo o Grau de Aversão à Desigualdade da População Brasileira Através dos Resultados do Bolsa-Família" (2012).

Elaboração própria.

3 A categoria de referência, omitida na tabela, é: pessoas que consideram a falta de esforço pessoal a principal causa da pobreza.

4 A categoria de referência, omitida na tabela, é "não branco", cuja descrição é: pessoas que autodeclaram ser de cor amarela, preta, pardo, ou de raça indígena. 
5 A categoria de referência, omitida na tabela é "não superior", cuja descrição é: pessoas com alfabetização, ensino fundamental ou médio como formação mais elevada concluída ou sem nenhuma instrução formal.

${ }^{6}$ A categoria de referência, omitida na tabela é "autônomos", cuja descrição é: pessoas que trabalham por conta própria.

${ }^{7}$ A categoria de referência, omitida na tabela, são indivíduos com renda inferior a $\mathrm{R} \$ 1.000,00$, inclusive os sem renda.

8 A categoria de referência, omitida na tabela, é: pessoas que consideram a falta de esforço pessoal a principal causa da pobreza.

9 A categoria de referência, omitida na tabela, é: pessoas que autodeclaram não pertencer a uma religião.

${ }^{10}$ A categoria de referência, omitida na tabela, é: pessoas que manifestam não ter uma vida religiosa ativa.

${ }^{11}$ A categoria de referência, omitida na tabela, é a região Sul.

Cruzando as variáveis de interesse, POUM e IPM, com algumas variáveis independentes se observa que, entre pessoas com renda de até $\mathrm{R} \$ 1.000,5 \%$ consideram que pioraram a situação econômica comparando-a com a de seus pais (IPM entre 1 e 2); na mesma faixa de renda, $46 \%$ acham que melhorou sua situação consideravelmente com respeito à posição econômica dos seus pais. No grupo das rendas superiores a $\mathrm{R} \$ 5.000$, observa-se uma ínfima percepção de que sua situação piorou - apenas $0,5 \%$ - face a $60 \%$ que manifestam ter melhorado sua situação comparando com a de seus pais. As expectativas sobre a situação dos filhos parecem indicar uma atitude otimista, em todas as faixas de renda. Na média, $75 \%$ consideram que seus filhos terão uma situação econômica melhor.

Com respeito à variável educação, analisando por separado pessoas com e sem ensino superior, uma porcentagem similar, $60 \%$ dos entrevistados, têm um IPM entre 4 e 5 . O comportamento otimista quanto ao futuro também não varia por nível de educação: $57 \%$ das pessoas sem ensino superior e $63 \%$ das pessoas que têm ensino superior, manifestam ter expectativas positivas sobre a situação futura de seus filhos. Cabe ressaltar que nas pessoas que reportaram ter ensino superior, 30\% têm uma renda superior a $\mathrm{R} \$ 5.000$, enquanto que, no grupo das pessoas sem ensino superior, a mesma porcentagem tem renda até $\mathrm{R} \$ 1.000$.

Por cor/raça, 55\% de brancos, bem como de não brancos, manifestam ter melhorado sua situação com respeito à situação de seus pais, e apenas $4 \%$ de cada um dos grupos consideram que piorou. Com uma ligeira diferença, 79\% versus 73\%, o grupo dos não brancos aparece mais otimista sobre o futuro de seus filhos frente ao grupo dos brancos. 
Por sexo, observa-se um comportamento similar tanto em IPM quanto em POUM: 55\% dos homens e a mesma porcentagem das mulheres consideram viver melhor que seus progenitores. Sobre o futuro, $75 \%$ esperam que seus filhos tenham uma situação superior.

Por regiões, em geral, a porcentagem de pessoas com IPM baixo, entre 1 e 2, é mínimo, 5\%. A percepção de uma situação melhor com respeito ao passado, IPM entre 4 e 5, é mais acentuada nas regiões menos desenvolvidas do Brasil, Norte e Nordeste, com 78 e $61 \%$ respectivamente. As pessoas das regiões mais ricas e desenvolvidas, Sul, Centro-Oeste e Sudeste, são menos positivas ao avaliar sua situação atual com a situação de seus progenitores (IPM alto manifestado por 44,51 e $55 \%$, respectivamente).

Com relação ao futuro, são os habitantes das mesmas regiões menos favorecidas os mais otimistas. No Norte, $91 \%$, e no Nordeste, $77 \%$, consideram que seus sucessores terão dias melhores. Nas outras regiões, uma visão positiva se mantém, contudo, essa parcela otimista é menor: na média 70\%, têm uma boa expectativa para seus filhos.

\section{Resultados e discussão}

Na Tabela 3 são apresentados os resultados dos modelos estimados, tanto para variáveis dependentes simples (Rl a R4), como para a variável composta (R5).

\subsection{Relação entre percepção de mobilidade passada e preferência por redistribuição}

Observando-se inicialmente os resultados da regressão que tem como variável dependente a variável composta (R5), que pode ser vista como uma síntese de preferências por redistribuição, nota-se que a mobilidade passada (IPM) mostra-se negativa e significativa, o que quer dizer que aqueles que consideram que houve forte melhoria na sua situação econômica com respeito aos últimos cinco anos são os menos favoráveis à redistribuição. 
Visto do ângulo inverso, quanto mais forte a percepção de uma evolução negativa da própria condição econômica, maior é o apoio à redistribuição. Pode-se interpretar que uma percepção de experiências negativas teria deixado os entrevistados mais sensíveis face ao tema redistributivo. Esse resultado poderia ser entendido como uma expressão da necessidade de proteção frente aos riscos, que adviria de políticas redistributivas.

Trata-se de efeito similar ao obtido por Silva e Figueiredo (2013) no seu estudo para a América Latina. Consistente com a teoria do aprendizado racional de Piketty (1995) o resultado mostra a importância das experiências de mobilidade passada nas preferências atuais das pessoas. Vale destacar que a variável se revela fortemente significativa, apesar da inclusão de uma série de variáveis de controle inspirada pela literatura.

Tabela 3 - Estimações da relação entre mobilidade econômica subjetiva e apoio à redistribuição no Brasil

\begin{tabular}{|c|c|c|c|c|c|c|c|}
\hline $\begin{array}{c}\text { Variável } \\
\text { dependente }\end{array}$ & $\begin{array}{l}\text { R1 (aversão à } \\
\text { desigualdade: } \\
\text { "distribuição é } \\
\text { preocupante") }\end{array}$ & $\begin{array}{l}\text { R2 (demanda } \\
\text { por redistribuição: } \\
\text { "desigualdade é } \\
\text { problema") }\end{array}$ & $\begin{array}{l}\text { R3 (demanda por } \\
\text { redistribuição: } \\
\text { "governo deve } \\
\text { reduzir desigual- } \\
\text { dades") }\end{array}$ & $\begin{array}{l}\text { R4 (apoio a } \\
\text { tributação } \\
\text { progressiva) }\end{array}$ & $\begin{array}{l}\text { R5* (variável } \\
\text { composta; } \\
\text { somatório } \\
\text { da quatro } \\
\text { anteriores) }\end{array}$ & $\begin{array}{l}\text { R5 Renda } \\
\text { maior do que } \\
\quad 4000\end{array}$ & $\begin{array}{l}\text { R5* Renda } \\
\text { menor do } \\
\text { que } 4000\end{array}$ \\
\hline \multirow{2}{*}{$\begin{array}{l}\text { POUM (expectati- } \\
\text { va de mobilidade } \\
\text { futura) }\end{array}$} & $0,2609^{* * *}$ & $0,2448^{* \star *}$ & $0,1840^{* *}$ & $0,1551^{\star}$ & $0,2560^{* * *}$ & $0.3724^{\star \star}$ & $0.2498^{* \star *}$ \\
\hline & $-0,0937$ & $-0,0948$ & $-0,0841$ & $-0,0824$ & $-0,0694$ & $(0.1812)$ & $(0.0758)$ \\
\hline \multirow{2}{*}{$\begin{array}{l}\text { IPM (percepção } \\
\text { de mobilidade } \\
\text { passada) }\end{array}$} & $-0,0938$ & $-0,4318^{* \star *}$ & $-0,1913^{\star \star}$ & 0,0291 & $-0,2106^{\star \star \star}$ & $-0.5190^{* * *}$ & $-0.1506^{* \star}$ \\
\hline & $-0,0923$ & $-0,0956$ & $-0,0818$ & $-0,079$ & $-0,0673$ & $(0.1838)$ & $(0.0731)$ \\
\hline \multirow{2}{*}{ Idade } & $-0,0013$ & $-0,0123$ & 0,0136 & $0,0470^{\star \star}$ & $0,0298^{*}$ & -0.0251 & $0.0385^{* *}$ \\
\hline & $-0,0219$ & $-0,0223$ & $-0,0191$ & $-0,0192$ & $-0,0157$ & $(0.0475)$ & $(0.0168)$ \\
\hline \multirow{2}{*}{ Idade $^{2}$} & 0 & 0,0001 & $-0,0001$ & $-0,0004$ & $-0,0003$ & 0.0004 & $-0.0004^{*}$ \\
\hline & $-0,0002$ & $-0,0003$ & $-0,0002$ & $-0,0002$ & $-0,0002$ & $(0.0005)$ & $(0.0002)$ \\
\hline \multirow{2}{*}{ Mulher } & 0,188 & $0,4422^{\star \star \star}$ & 0,138 & $-0,0688$ & $0,1973^{\star *}$ & $0.4392^{*}$ & 0.1623 \\
\hline & $-0,1291$ & $-0,1256$ & $-0,1108$ & $-0,1087$ & $-0,0909$ & $(0.2354)$ & $(0.0995)$ \\
\hline \multirow{2}{*}{ Casado } & 0,1812 & $-0,0144$ & 0,1733 & 0,0183 & 0,0549 & 0.2426 & 0.0394 \\
\hline & $-0,1306$ & $-0,1272$ & $-0,1132$ & $-0,1109$ & $-0,0931$ & $(0.2709)$ & $(0.1003)$ \\
\hline \multirow{2}{*}{ Branco } & 0,061 & 0,1531 & $-0,0545$ & $-0,1968^{\star}$ & $-0,0535$ & 0.1531 & -0.1072 \\
\hline & $-0,1348$ & $-0,1322$ & $-0,1161$ & $-0,1137$ & $-0,0953$ & $(0.2415)$ & $(0.1041)$ \\
\hline \multirow{2}{*}{ Superior } & 0,3122 & 0,1107 & 0,1756 & $0,3433^{* *}$ & $0,2778^{* *}$ & 0.2350 & $0.2963^{*}$ \\
\hline & $-0,2139$ & $-0,1931$ & $-0,171$ & $-0,1676$ & $-0,1377$ & $(0.2577)$ & $(0.1684)$ \\
\hline \multirow{2}{*}{ Formal } & 0,1841 & 0,2477 & $0,5058^{\star \star \star}$ & 0,0244 & $0,3297^{\star \star \star}$ & $0.8157^{\star \star \star}$ & $0.2428^{*}$ \\
\hline & $-0,1656$ & $-0,1579$ & $-0,1422$ & $-0,1391$ & $-0,1172$ & $(0.3044)$ & $(0.1281)$ \\
\hline \multirow{2}{*}{ Informal } & $-0,0035$ & 0,0367 & 0,277 & 0,106 & 0,1651 & $1.4307^{\star \star \star}$ & 0.0180 \\
\hline & $-0,2247$ & $-0,2214$ & $-0,1987$ & $-0,1937$ & $-0,1633$ & (0.5473) & $(0.1728)$ \\
\hline
\end{tabular}


Tabela 3 - Estimações da relação entre mobilidade econômica subjetiva e apoio à redistribuição no Brasil (Continuação)

\begin{tabular}{|c|c|c|c|c|c|c|c|}
\hline $\begin{array}{c}\text { Variável } \\
\text { dependente }\end{array}$ & $\begin{array}{l}\text { R1 (aversão à } \\
\text { desigualdade: } \\
\text { "distribuição é } \\
\text { preocupante") }\end{array}$ & $\begin{array}{l}\text { R2 (demanda } \\
\text { por redistribuição: } \\
\text { "desigualdade é } \\
\text { problema") }\end{array}$ & $\begin{array}{l}\text { R3 (demanda por } \\
\text { redistribuição: } \\
\text { "governo deve } \\
\text { reduzir desigual- } \\
\text { dades") }\end{array}$ & $\begin{array}{l}\text { R4 (apoio a } \\
\text { tributação } \\
\text { progressiva) }\end{array}$ & $\begin{array}{l}\text { R5* (variável } \\
\text { composta; } \\
\text { somatório } \\
\text { da quatro } \\
\text { anteriores) }\end{array}$ & $\begin{array}{l}\text { R5* Renda } \\
\text { maior do que } \\
4000\end{array}$ & $\begin{array}{l}\text { R5 }{ }^{*} \text { Renda } \\
\text { menor do } \\
\text { que } 4000\end{array}$ \\
\hline \multirow{2}{*}{$\begin{array}{l}\text { Não pertence } \\
\text { à força laboral }\end{array}$} & $-0,0162$ & 0,1695 & 0,0002 & 0,1957 & 0,1256 & $0.6726^{*}$ & 0.0340 \\
\hline & $-0,1839$ & $-0,1836$ & $-0,1575$ & $-0,1617$ & $-0,1316$ & $(0.3717)$ & $(0.1425)$ \\
\hline \multirow{2}{*}{$\begin{array}{c}1001<\text { Ren- } \\
\text { da<2000 }\end{array}$} & 0,2586 & $0,3806^{* *}$ & 0,1996 & $-0,0536$ & $0,2055^{\star}$ & & 0.1949 \\
\hline & $-0,1592$ & $-0,1633$ & $-0,1467$ & $-0,1427$ & $-0,1196$ & & $(0.1202)$ \\
\hline \multirow{2}{*}{$\begin{array}{c}2001<\text { Ren- } \\
\text { da<3000 }\end{array}$} & $0,6417^{\star \star \star}$ & $0,5500^{\star \star \star}$ & 0,1433 & 0,1139 & $0,4088^{* * *}$ & & $0.3841^{* * *}$ \\
\hline & $-0,2087$ & $-0,1998$ & $-0,1754$ & $-0,1739$ & $-0,1457$ & & $(0.1478)$ \\
\hline \multirow{2}{*}{$\begin{array}{c}3001<\text { Ren- } \\
\text { da<5000 }\end{array}$} & $0,6016^{\star \star \star}$ & $0,4781^{* \star}$ & $-0,176$ & $-0,0831$ & 0,1789 & -0.0654 & 0.1773 \\
\hline & $-0,2157$ & $-0,2046$ & $-0,1772$ & $-0,1772$ & $-0,1491$ & $(0.2457)$ & $(0.1689)$ \\
\hline \multirow{2}{*}{ Renda $>5000$} & $0,4823^{\star}$ & 0,2211 & 0,1116 & $-0,0151$ & 0,1981 & & \\
\hline & $-0,2484$ & $-0,2329$ & $-0,215$ & $-0,212$ & $-0,1755$ & & \\
\hline \multirow{2}{*}{$\begin{array}{c}\text { Falta de } \\
\text { oportunidades }\end{array}$} & $0,2471^{*}$ & 0,2123 & $0,3920^{\star \star \star}$ & $0,6551^{\star * \star}$ & $0,4981^{\star \star \star}$ & $1.0436^{\star \star *}$ & $0.4306^{\star * *}$ \\
\hline & $-0,1431$ & $-0,1415$ & $-0,1242$ & $-0,122$ & $-0,1016$ & $(0.2832)$ & $(0.1101)$ \\
\hline \multirow{2}{*}{$\begin{array}{c}\text { Esforço \& } \\
\text { Oportunidade }\end{array}$} & 0,0753 & $-0,1288$ & 0,175 & $0,4016^{\star \star \star}$ & $0,2417^{\star \star}$ & 0.1527 & $0.2775^{\star \star}$ \\
\hline & $-0,1578$ & $-0,1503$ & $-0,1349$ & $-0,1319$ & $-0,1121$ & $(0.2713)$ & $(0.1243)$ \\
\hline \multirow{2}{*}{ Religiosos } & $-0,3606$ & $-0,4641$ & $-0,7374$ & $-0,5506$ & $-0,8478^{\star *}$ & -0.1585 & $-0.8975^{\star *}$ \\
\hline & $-0,5102$ & $-0,5077$ & $-0,4695$ & $-0,447$ & $-0,3646$ & $(0.7611)$ & $(0.4228)$ \\
\hline \multirow{2}{*}{ Praticantes } & $-0,0078$ & 0,1323 & $0,1914^{*}$ & $-0,0782$ & 0,1361 & 0.0317 & 0.1420 \\
\hline & $-0,1279$ & $-0,1247$ & $-0,1106$ & $-0,1078$ & $-0,0911$ & $(0.2373)$ & $(0.0994)$ \\
\hline \multirow{2}{*}{$\begin{array}{l}\text { Conhece } \\
\text { beneficiário }\end{array}$} & $-0,2422^{*}$ & 0,148 & $-0,0113$ & $-0,0091$ & $-0,0359$ & -0.2605 & 0.0090 \\
\hline & $-0,1356$ & $-0,1349$ & $-0,1192$ & $-0,1185$ & $-0,0992$ & $(0.2427)$ & $(0.1100)$ \\
\hline \multirow{2}{*}{ Sudeste } & $0,4604^{\star \star *}$ & $-0,1993$ & $-0,2539$ & 0,1116 & 0,0755 & 0.0594 & 0.0839 \\
\hline & $-0,1784$ & $-0,1914$ & $-0,1698$ & $-0,1662$ & $-0,1407$ & $(0.3706)$ & $(0.1542)$ \\
\hline \multirow{2}{*}{ Norte } & $1,0328^{\star \star \star}$ & $-0,0654$ & $-0,3401^{*}$ & 0,0226 & 0,1308 & -0.1398 & 0.1208 \\
\hline & $-0,2235$ & $-0,2113$ & $-0,1869$ & $-0,1844$ & $-0,1536$ & $(0.4813)$ & $(0.1636)$ \\
\hline \multirow{2}{*}{ Nordeste } & $0,9807^{\star \star \star}$ & $0,5650^{\star \star \star}$ & $0,3697^{\star \star}$ & 0,1305 & $0,5366^{\star \star *}$ & 0.0472 & $0.5810^{\star * *}$ \\
\hline & $-0,1972$ & $-0,2099$ & $-0,1822$ & $-0,1709$ & $-0,1427$ & $(0.4376)$ & $(0.1522)$ \\
\hline \multirow{2}{*}{ Centro-Oeste } & $0,5728^{\star \star *}$ & $-0,5230^{\star *}$ & $-0,3832^{\star \star}$ & $-0,151$ & $-0,1614$ & -0.3424 & -0.1392 \\
\hline & $-0,211$ & $-0,2096$ & $-0,1887$ & $-0,1845$ & $-0,1569$ & $(0.3710)$ & $(0.1792)$ \\
\hline $\mathrm{N}$ & 1830 & 1830 & 1830 & 1830 & 1830 & 297 & 1535 \\
\hline McFadden's $\mathrm{R}^{2}$ & 0,05 & 0,045 & 0,037 & 0,034 & 0,024 & 0,064 & 0.023 \\
\hline$R^{2}$ count & 0,805 & 0,795 & 0,709 & 0,697 & 0,422 & 0,438 & 0,422 \\
\hline
\end{tabular}

Erros padrão em parêntesis ${ }^{*} \mathrm{p}<0.10,{ }^{* *} \mathrm{p}<0.05,{ }^{* * *} \mathrm{p}<0.01$. R5* Modelo logit ordenado: a escala de R5 varia entre 0 e 4 . Para conservar a opinião dos entrevistados em cada pergunta, optou-se por trabalhar com um modelo logit ordenado, com o intuito de manter a escala original de R5. 
Também são negativas as relações entre percepção de mobilidade passada (IPM) e as variáveis que expressam demanda por redistribuição em situações abstratas (R2 e R3, ambas significativas), e as interpretações seriam semelhantes às delineadas para a relação de IPM com R5. Grosso modo, quanto menor o valor atribuído por um indivíduo à evolução de sua situação econômica, maiores as chances de ele se mostrar insatisfeito com o status quo distributivo e apoiar um combate à desigualdade. Os coeficientes associados às variáveis de aversão à desigualdade (Rl) e à tributação progressiva (R4) não são estatisticamente significativos.

\subsection{Relação entre expectativa de mobilidade futura e preferência por redistribuição}

Em todas as estimações, as variáveis de expectativas de mobilidade futura são positivas, embora a magnitude vá caindo quando se caminha do modelo cuja variável dependente é $\mathrm{Rl}$ até aquele cuja variável dependente é R4. No Brasil, observa-se o curioso fenômeno de que os mais otimistas sobre o seu futuro e de seus filhos seriam os mais favoráveis a políticas redistributivas, ao menos tais como expressas pelas variáveis de que dispomos na base de dados ora em uso.

Por um lado, tais resultados causam certo desconforto, uma vez que não somente refutam a previsão teórica consubstanciada na chamada "hipótese POUM", corroborada em estudos realizados em países desenvolvidos - visto que o sinal aqui não é negativo, como esperado - mas mais do que isto: chegam a inverter completamente a expectativa, dado que se obteve sinal positivo e significativo. Por outro lado, há de se dizer que os resultados ora apresentados vão ao encontro daqueles de Silva e Figueiredo (2013), que chegaram a um resultado similar na análise feita para a região latino-americana e na qual manifestam que o Brasil segue a tendência regional. Reforçase, portanto, esse resultado segundo a qual na América Latina em geral, e no Brasil em particular, o grau de otimismo com o futuro não reduz - ao contrário, aumenta - as aspirações por uma distribuição mais igualitária e uma intervenção do governo a fim de reduzir desigualdade. Ainda não há, até onde sabemos, um quadro teórico capaz de explicar de modo convincente este resultado. 
Antes de levantar hipóteses explicativas, cabe mencionar que uma análise adicional foi realizada, rodando-se regressões (para R5) separadas para pessoas com renda familiar de até $\mathrm{R} \$ 4$ mil e com renda superior a tal valor, com o intuito de observar se haveria eventuais diferenças nos coeficientes dos grupos. Esta separação permitiria verificar se há comportamentos diferentes entre os mais ricos e os demais cidadãos, com eventual referência a aspectos reportados na literatura como o autointeresse e a incerteza. Contudo, os resultados tão-somente confirmaram os principais resultados já discutidos da Tabela 3: nas estimações de ambas as subamostras, obtiveram-se coeficientes negativos e significativos para a percepção de mobilidade passada (IPM) e coeficientes positivos e significativos para a expectativa mobilidade futura (POUM).

Em ambientes de instabilidade política, sem um panorama claro sobre a manutenção das políticas redistributivas, e no caso de que os entrevistados considerem um prazo menor ao exigido pela POUM, a hipótese poderia não se observar (Silva e Figueiredo, 2013). As condições políticas do Brasil, no momento das entrevistas, não sugerem um quadro de instabilidade política e o horizonte temporal das perguntas faz referência a 5 anos, destarte, estas razoes pareceriam não explicar a não observação da POUM no Brasil. A incerteza associada a processos de mobilidade econômica referida por Figueiredo (2009) parece se ajustar melhor ao observado no Brasil, onde os agentes talvez se sentissem inseguros e por isso demandavam proteção estatal.

\subsection{Breve exposição e discussão sobre demais variáveis}

No que se refere às demais variáveis, que não aquelas referentes a percepções de mobilidade, de modo geral os resultados obtidos estão dentro do esperado. Assim sendo, não requereriam maiores comentários caso se tratasse de um artigo que abordasse países já bastante estudados na literatura internacional, todavia, como a que trata do Brasil ainda é incipiente, aqui ao menos uma breve exposição e discussão dos resultados encontrados. A não ser quando indicado o contrário, os comentários feitos nesta subseção referem-se à regressão cuja variável dependente é a composta (R5). 
As mulheres aparecem como mais favoráveis a redistribuir. Esse resultado é consistente com Ravaillon e Lokshin (2000), Corneo e Grüner (2002), Alesina e La Ferrara (2005), Gaviria (2007), Linos e West (2003). Os últimos autores fazem referência a várias teorias e manifestam que as mulheres poderiam ser mais sensíveis ao bem-estar dos outros. Também oferecem uma explicação relacionada com a maximização de utilidade, considerando que as mulheres apoiariam mais políticas redistributivas pelo fato de, em geral, terem condições mais difíceis no mercado de trabalho se comparadas com os homens. Aspectos como idade, estado civil e cor pareceriam não ter muita influência na demanda por redistribuição no Brasil, a exemplo do que se observou em Silva e Figueiredo (2013) para a América Latina.

As pessoas com níveis de educação mais elevados se mostram mais favoráveis à redistribuição. A influência da educação na determinação das preferências individuais por redistribuição não tem sido explicada totalmente nos estudos existentes. No caso do efeito positivo, para Linos e West (2003) pessoas educadas poderiam ter uma melhor compreensão dos benefícios da redistribuição e de uma sociedade igualitária. Em alguns estudos, porém, a variável tem um efeito negativo (Alesina e La Ferrara, 2005; Linos e West, 2003; Fong, 2001).

Como esperado, e conforme Piketty (1995), as pessoas que consideram que a falta de oportunidades é a principal causa da pobreza mostram-se favoráveis à redistribuição. Na mesma linha os resultados de Gaviria (2007) sugerem que as pessoas que não reconhecem o papel do esforço como fundamental para alcançar sucesso econômico são partidárias da redistribuição. Corneo e Grüner (2002) mostram o efeito significativamente negativo da variável "chave para o sucesso é trabalhar duro", quer dizer, os indivíduos que atribuem alto valor ao papel do esforço preferem menores níveis de redistribuição. No Brasil, Reis (2000) sugere que é atribuído um papel prioritário à educação como fonte de ascensão social e econômica. Entende-se que a educação poderia ser vista como parte do esforço dos indivíduos para alcançar o progresso econômico e social.

Os trabalhadores formais seriam mais favoráveis à redistribuição do que os autônomos. Apesar de aventarem a possibilidade de que autônomos seriam menos favoráveis a políticas redistributivas por serem menos avessos ao risco, Alesina e La Ferrara (2005) oferecem ex- 
plicações alternativas, pensadas para o contexto de países desenvolvidos: (a) pessoas autônomas se beneficiariam menos de programas estatais, razão pela qual não seriam favoráveis à redistribuição; (b) certo grau de individualismo poderia, simultaneamente, ser motor para o empreendedorismo e um dos motivos para uma atitude não redistributiva e valorizadora do esforço individual; (c) este tipo de emprego poderia ser uma mera alternativa ao desemprego e não uma opção; e (d) é uma atividade que depende do acesso ao crédito. Em países em desenvolvimento, a decisão de exercer uma atividade como autônomo deve-se, com alta probabilidade, a outras razões além da atitude frente ao risco.

A variável de renda familiar foi significativa em alguns casos, revelando uma atitude redistributiva positiva nas faixas intermediárias. Este resultado traz duas reflexões. Primeiro, a exemplo de Fong (2001), o fator econômico não é um forte previsor das preferências por redistribuição, contradizendo a hipótese de Meltzer e Richard (1981). Confirma-se a relevância de incluir outros fatores não pecuniários para analisar a demanda por redistribuição. Por outro lado, algumas limitações da variável ${ }^{12}$ também podem ter influenciado nos resultados. Contudo, nos modelos realizados sem esta variável, observaram-se resultados similares aos obtidos com os modelos que contêm a variável renda familiar.

Segundo, o resultado observado nas faixas intermediárias nos remete à atual discussão de acadêmicos - da Economia e da Sociologia - e de policy makers, que tentam vislumbrar uma teoria de classes sociais para o Brasil contemporâneo, e em particular que permita entender as características e fronteiras da "nova classe média". É importante entender quem conforma essa classe média que manifesta seu apoio às políticas redistributivas. Quais as características desta nova classe média? Para Kerstenetzky et al. (2013), a nova classe média brasileira estaria distante dos padrões da classe média tradicional, pois não exibe nem pelo menos a segurança econômica que caracteriza a esta classe. Ferreira et al. (2013) postulam que não se pode deixar de lado a heterogeneidade da "nova classe média", uma vez que seus membros mais próximos à pobreza seriam mais vulneráveis a choques macroeconômicos. A sustentabilidade do consumo baseado principalmente no crédito também é questionada pelos autores.

12 Por exemplo, a renda é familiar e há uma porcentagem não desprezível de missings. 
Reconhece-se a influência da religião no comportamento econômico individual desde Max Weber, com trabalhos atuais que confirmam esta hipótese (Barro e McCleary, 2007; Guiso et al., 2003). No que tange às preferências por redistribuição, os resultados sugerem que pessoas religiosas seriam menos favoráveis a redistribuir, pois a religiosidade funcionaria, para indivíduos religiosos, como uma espécie de "seguro" contra fatos adversos. Neste trabalho o grau de religiosidade não se mostra relevante.

Os habitantes da região Nordeste aparecem como mais favoráveis à redistribuição se comparados com a categoria de referência (habitantes da região Sul). Esse resultado pode estar relacionado, mesmo após a inclusão de controles, com o nível de desigualdade e pobreza existente nessa região - espera-se uma maior disposição para redistribuir nas regiões mais desiguais e mais pobres (Meltzer e Richard, 1981).

\section{Conclusões}

O estudo das preferências por redistribuição requer a consideração de diversos aspectos, pois a situação econômica individual não é suficiente para compreender o que levaria os cidadãos de um país a apoiar ou não uma política redistributiva. De fato, diversos pesquisadores em países desenvolvidos e em desenvolvimento têm produzido trabalhos teóricos e empíricos que confirmam o caráter multidimensional das preferências por redistribuição.

Este trabalho é uma contribuição empírica para o estudo das preferências por redistribuição, aplicada a um país em desenvolvimento, com forte desigualdade e com histórico recente de melhoria de vida da população (relativa redução de desigualdade e de pobreza). Num nível descritivo, conclui-se que: o nível de desigualdade de renda vigente é um aspecto que os brasileiros declaram que os incomoda; em geral, os brasileiros declaram apoiar medidas redistributiva, ao menos quando lhes são apresentadas em forma abstrata e sem custos diretos; em termos um pouco mais concretos, são favoráveis à progressividade de impostos. Por si só, estas são constatações importantes para acadêmicos e políticos para formuladores de política. 
Quanto aos resultados de regressões, coincidindo com outros trabalhos realizados para países desenvolvidos, apresentam-se evidências de que mulheres, trabalhadores formais, pessoas com maiores níveis de educação e habitantes das regiões mais desiguais e mais carentes seriam mais favoráveis a redistribuir, ao contrário de indivíduos que consideram que a principal causa da pobreza é a falta de esforço. Não obstante a possibilidade de múltiplas leituras de resultados nas estimações realizadas, concentrou-se a atenção na relação entre mobilidade econômica - expressa por percepções de mobilidade passada e expectativa de mobilidade futura - e aversão à desigualdade, e também entre mobilidade econômica e demanda por redistribuição.

Confirmou-se a importância das experiências passadas na determinação de uma postura redistributiva, observando-se que as pessoas que perceberam uma piora com respeito a sua situação econômica no passado mostraram-se mais propensas a favorecer medidas redistributivas. No contexto atual, em que Brasil e outros países latino-americanos, bem como muitos países ditos "emergentes", voltam a enfrentar dificuldades econômicas consideráveis, com queda de preço de commodities, refreamento do ritmo de crescimento econômico e incidências de desequilíbrios em variáveis macroeconômicas importantes, é possível que as experiências percebidas de mobilidade passada pouco a pouco se deteriorem - possivelmente de forma contundente, dada a comparação com a generosa década de 2000, ainda fresca na memória. Paradoxalmente, a confiar em nossos resultados, essa tendência de se ter um olhar mais negativo sobre o passado recente pode colocar mais pressão para manutenção ou incremento de gastos sociais, justamente quando certos setores da sociedade recomendam mais austeridade. Tensões podem advir desses reclamos contraditórios.

As expectativas de mobilidade futura também se mostraram significativas, porém, de modo contrário ao previsto pelos modelos teóricos mais importantes e ao que se observa na literatura que aborda países desenvolvidos, a relação mostrou-se positiva: mais otimistas com relação ao futuro declaram-se menos conformados com a desigualdade e mais demandantes de redistribuição. Cabe lembrar, porém, que há alguma regularidade nesse resultado: outros estudos cujo foco foi a América Latina chegaram às mesmas conclusões. Na seção anterior, lançamos algumas hipóteses para explicar esse resultado inesperado, mas certamente um esforço teórico específico será necessário 
para explicá-lo adequadamente, assim como serão bem-vindos mais estudos empíricos - inclusive com a exploração de outras bases e preferencialmente com dados longitudinais - pois ainda é incipiente a produção que trata das preferências por redistribuição neste continente.

No que se refere às implicações práticas de tal resultado inesperado, primeiro resta saber se o otimismo manifestado na época de coleta dos dados em 2012 se mantém neste momento, e se será mantido no futuro próximo, em condições econômicas menos alvissareiras, como já dito. Caso se mantenha o otimismo, e se preserve a relação positiva de otimismo com demanda por redistribuição, teremos mais um canal para impulsionar partidos cuja plataforma política privilegie a redistribuição.

Concluímos com a resposta a um questionamento frequentemente dirigido aos estudos sobre preferências acerca de questões redistributivas. Trata-se de certo receio quanto à validade dos resultados, a qual seria demasiado delimitada, tanto espacialmente, como temporalmente: qual seria então a relevância de resultados específicos e não generalizáveis? Como resposta, destacam-se dois elementos. Em primeiro lugar, cabe concordar que a validade das hipóteses pode ser afetada por uma série de variáveis de contexto, e que pode haver mudanças ao longo do tempo - algo compreendido na literatura como um exemplo de endogeneidade das preferências (Bowles e Gintis, 2001). A este respeito, pode-se ressaltar que a própria evolução da oferta de políticas sociais pode modificar as preferências dos indivíduos - fenômeno às vezes chamado de "efeito feedback" ou de "circularidade das preferências por redistribuição" (Alesina e FuchsSchündeln, 2006). Um exemplo concreto para o caso brasileiro seria o seguinte: antes do advento e da popularização das políticas de transferência de renda em larga escala, é possível que o grau de apoio a políticas deste tipo fosse relativamente baixo, por mero desconhecimento, e que agora a própria existência e disseminação da política tenha aumentado o apoio à sua preservação.

Em segundo lugar, sem desprezar a crítica à possível especificidade temporal e espacial dos resultados, é preciso relembrar que uma série de padrões e regularidades vêm sendo observadas na literatura internacional, de modo que é possível acumular conhecimento na área de preferências em matérias redistributivas, conhecimento este 
que não será completamente volátil ou fugidio. $\mathrm{O}$ exemplo mais claro é o contraste entre preferências de cidadãos da Europa e Estados Unidos, identificado por De Tocqueville há quase dois séculos e vigente até hoje.

\section{Referências}

ABATEMARCO, Antonio. Is income mobility socially desirable? Technical report, University of Napoli, 2004

ALESINA, Alberto; ANGELETOS, George-Marios. Fairness and redistribution. American Economic Review. V. 95, n. 4, p. $960-980,2005$.

ALESINA, Alberto; FUCHS-SCHÜNDELN, Nicola. Good-Bye Lenin (or not?): The effect of Communism on people's preferences. American Economic Review. V. 97, n. 4, p. 1507-1528, 2006.

ALESINA, Alberto; GIULIANO, Paola. Preferences for redistribution. In: BENHABI, J.; JACKSON, M.; BISIN, A. (Org.). Handbook of Social Economics. The Netherlands: North Holland, V. 1A, p. $93-131,2011$.

ALESINA, Alberto; GLAESER, Edward; SACERDOTE, Bruce. Why Doesn't the United States have a European-Style welfare state? Brookings Papers on Economic Activity. V. 2, 2001.

ALESINA, Alberto; LA FERRARA, Eliana. Preferences for redistribution in the land of opportunities. Journal of Public Economics. V. 89, p. 897-931, 2005.

ANTIGO, Mariangela; Machado Ana Flávia. Mobilidade intrageracional de rendimentos no Brasil. Revista de Economia Política. V. 33 (1), p. 166-178, 2013.

BARRO, Robert; McCLEARY, Rachel, Political Economy and Religion in the Spirit of Max Weber. Stanford University Press, 2007.

BÉNABOU, Roland; OK, Efe. Social mobility and the demand for redistribution: The Poum hypothesis. The Quarterly Journal of Economics. V. 116, n. 2, p. 447-487, 2001.

BÉNABOU, Roland; TIROLE, Jean. Belief in a just world and redistributive politics. The Quarterly Journal of Economics. V. 121, n. 2, p. 699-746, 2006.

BOWLES, Samuel; GINTIS, Herbert. ¿Ha pasado de moda la igualdad? El Homo reciprocans y el futuro de las politicas igualitaristas. In: GARGARELLA, R.; OVEJERO, F. (Org.). Razones para el Socialismo. Ed. Paidós, Barcelona - España. 2001. ISBN 84-493-119-5, 2001.

BRITO, Alessandra; FOGUEL, Miguel; KERSTENETZKY, Celia. Afinal, Qual A Contribuição Da Política De Valorização Do Salário Mínimo Para A Queda Da Desigualdade No Brasil? Uma Estimativa Para O Período 1995-2013. Discussion Paper No. 109, Center for Studies on Inequality and Development (CEDE), Dezembro, 2015.

CHECHI, Daniele; FILIPPIN, Antonio. An experimental study of the POUM hypothesis. In: COWELL, F. (ed.). Inequality, Welfare and Income Distribution: Experimental Approaches. Emerald Group Publishing Limited, v. 11, p. 115-136, 2011.

COJOCARU, Alexandru. Prospects of upward mobility and preferences for redistribution: Evidence from the Life in Transition Survey. European Journal of Political Economy. V. 34, p. 300-314, 2014.

CORNEO, Giacomo; GRÜNER, Hans Peter. Individual preferences for political redistribution. Journal of Public Economics, V. 83, p. 83-107, 2002.

CRAMER Brian; KAUFMAN, Robert. Views of economic inequality in Latin America. Comparative Political Studies. V. 44 (9), p. 1206-37, 2011. 
CRUCES, Guillermo; PEREZ, Ricardo; TETAZ, Martin. Biased perceptions of income distribution and preferences for redistribution: Evidence from a survey experiment. Journal of Public Economics. V. 98, p. 100-112, 2013.

DE TOCQUEVILLE, Alexis. Democracy in America. Nueva York, Penguin Classics. 2003. Publicação original em 1835.

FERREIRA, Francisco; LEITE, Phillippe; LICHFIELD, Julie; ULYSSEA, Gabriel. Ascensão e queda da desigualdade de renda no Brasil. Econômica. V. 8, n. 1, p. 147-169, junho 2006.

FERREIRA, Francisco; MESSINA, Julian; RIGOLINI, Jamele; LÓPEZ-CALVA, Luis-Felipe; LUGO; Ana María; VAKIS; Renos. Economic Mobility and the Rise of the Latin American Middle Class. World Bank Latin American and Caribbean Studies No. 11858. Washington, D.C.: World Bank, 2013.

FERREIRA, Sergio; VELOSO, Fernando. Intergenerational mobility of wages in Brazil. Brazilian Review of Econometrics. V. 26, p.181-211, 2006.

FIELDS, Gary. Economic and social mobility really are multifaceted. Paper presented on Frontiers on Social and Economic Mobility Conference. New York: Cornell University, March 2004.

FIELDS, Gary; OK, Efe. The measurement of income mobility: An introduction to the literature [Electronic version]. In J. Silber (Ed.) Handbook on income inequality measurement (pp. 557-596). Norwell, MA: Kluwer Academic Publishers, 1999.

FIGUEIREDO, Erik. O impacto da mobilidade de renda sobre o bem-estar econômico no Brasil. Economia Aplicada. V. 13 (3), 2009.

FIGUEIREDO, Erik; ZIEGELMANN, Flávio Augusto. Algumas Simulações de Efeitos de Mobilidade de Renda Sobre o Nível de Bem-Estar. Revista Brasileira de Economia. V. 63, 2009.

FONG, Cristina. Social Preferences, Self-Interest and the Demand for Redistribution. Journal of Public Economics, V. 82, p. 225 - 246, 2001.

FRIEDMAN, Milton, Capitalism and Freedom. Chicago: University of Chicago Press, 1962.

GAVIRIA, Alejandro. Social Mobility and Preferences for Redistribution in Latin America. Economía, V. 8, n. 1, p. 55-96, 2007.

GRAHAM, Carol; PETTINATO, Stefano. Happiness and hardship: Opportunity and insecurity in new market economies. World Economics. V.1, n. 4, p. 73-112, Outubro - Dezembro 2000.

GUISO, Luigi; SAPIENZA, Paola; ZINGALES, Luigi. People's opium? Religion and economic attitudes. Journal of Monetary Economics V. 50, p. 225-282, 2003.

HIRSCHMAN, Albert; ROTSCHILD, Michael. The changing tolerance for income inequality in the course of economic growth. Quarterly Journal of Economics, V. 87, n. 4, p. 544-566, 1973.

KERTENETZKY, Celia; UCHOA, Christiane; Silva, Nelson. Padrões de consumo e estilos de vida da “nova classe média". $37^{\circ}$ ENCONTRO NACIONAL DAANPOC, Águas de Lindóia, Setembro de 2013.

LINOS, Katerina; WEST, Martin. Self-interest, social beliefs, and attitudes to redistribution: Readdressing the issue of cross-national variation. European Sociological Review. V. 19, n. 4, p. 393-409, 2003.

LONDOÑO, Juliana. Movilidad social, preferencias redistributivas y felicidad en Colombia. Revista Desarrollo y Sociedad. II semestre, N. 68, p. 171-212, 2011.

MELTZER, Allan; RICHARD, Scott. A rational theory of the size of government. Journal of Political Economy. V. 89, p. 914-927, 1981.

NASCIMENTO, Marcos Aurélio; SOUZA, André Portela. Medidas e determinantes dos rendimentos do trabalho no Brasil. ENCONTRO NACIONAL DE ECONOMIA, Natal, 2005.

PASTORE, José; SILVA, Nelson. Mobilidade social no Brasil. Makron Books. São Paulo, 2000.

Estud. Econ., São Paulo, vol.46, n.1, p. 91-125, jan.-mar. 2016 
PERO, Valéria. Mobilidade social no Rio de Janeiro. Revista de Economia Mackenzie. V. 4, n. 4, p. 136-153, 2006.

PIKETTY, Thomas. Social mobility and redistributive politics. The Quarterly Journal of Economics. V. 110, n. 3, p. 551-584, 1995.

PITTAU, Maria Grazia; MASSARI, Riccardo; ZELLI, Roberto. Hierarchical modeling of disparities in preferences for redistribution. Oxford Bulletin of Economics and Statistics. V. 75, n. 4, p. 556-584, 2013.

RAVAILLON, Martin; LOKSHIN, Michael. Who want to redistribute? The tunnel effect in 1990 Russia. Journal of Public Economics. V. 76, p. 87-104, 2000.

REIS, Elisa. Percepções da elite sobre pobreza e desigualdade. Revista Brasileira de Ciências Sociais. V. 15, n. $42,2000$.

RIBEIRO, Carlos Antonio. Estrutura de classe e mobilidade social no Brasil. Bauru, São Paulo, Edusc. 2007. 312 p.; $23 \mathrm{~cm}$.

, Quatro décadas de mobilidade social no Brasil, DADOS - Revista de Ciências Sociais. Rio de Janeiro, v. 55, n. 3, p. 641- 679, 2012.

ROCHA, Rudi, URANI, André. Posicionamento social e a hipótese da distribuição de renda desconhecida. Brasil: quão pobres, quão ricos e quão desiguais nos percebemos?. Revista de Economia Política. São Paulo, v. 27, n. 4, p. 595-615, outubro-dezembro 2007.

SCHEVE, Kenneth; STASAVAGE, David. Religion and preferences for social insurance. Quarterly Journal of Political Science. V. 1, p. 255-286, 2006.

SILVA, Cleiton; FIGUEIREDO, Erik. Movilidad social y demanda de redistribución del ingreso en América Latina. Revista de la CEPAL, v. 110, p. 69-84, 2013.

SOARES, Sergei. Análise de bem-estar e decomposição por fatores da queda na desigualdade entre 1995 e 2004. Econômica, v. 8, p. 83-115, 2006.

STEGMUELLER, Daniel; SCHEEPERS, Peer; ROB DEUTSCHER, Sigrid; DE JONG, Eelke. Support for Redistribution in Western Europe. Assessing the role of religion. European Sociological review. V. 16, p. 1 - 16, 2011.

TOTH, István; KELLER, Tamás. Income Distribution, Inequality Perceptions, and Redistributive Preferences in European. In Gornick, J.C. \& Jäntti, M. (Eds), Income Inequality: Economic Disparities and the Middle Class in Affluent Countries (pp.173-203), California: Stanford University Press, 2014.

WALTENBERG, Fábio. Are Latin Americans - Brazilians in particular - willing to support an unconditional citizen's income?, In: LO VUOLO, R. (Org.). Citizen's Income and Welfare Regimes in Latin America. From Cash Transfers to Rights. 2013. Palgrave Macmillan, January 2013. 286 p. ISBN: 978-0-230-33821-0.

\section{$\underline{\text { Anexo } 1}$}

O survey "Medindo o Grau de Aversão à Desigualdade da População Brasileira Através dos Resultados do Bolsa-Família", foi desenvolvido com a coordenação de pesquisadores de Universidade Federal do Rio de Janeiro, RJ e colaboração de pesquisadores da Universidade Federal Fluminense, RJ. Para tal efeito, se entrevistaram 2.226 pessoas com 16 anos ou mais de idade. O objetivo do survey é investigar 
a percepção da população brasileira sobre temas como redução da miséria, da pobreza e da desigualdade.

Quatro grandes áreas foram abordadas na pesquisa: "apoio a políticas universais; ao papel do governo no combate às desigualdades e na promoção do bem-estar; à progressividade do sistema tributário; ao reconhecimento do direito, em caso de necessidade, à proteção de forma incondicional". As perguntas foram redigidas baseando-se nas questões de pesquisas existentes como a World Values Survey que vem sendo desenvolvida desde 1981 em 100 países com o intuito de coletar informações relacionadas com valores e crenças em temas como: democracia, tolerância com grupos étnicos minoritários, religião, globalização, meio ambiente, trabalho, família, e política, entre outros.

Aplicou-se um questionário estruturado com 54 perguntas fechadas subdivididas em oito temas: i) Satisfação com a vida; ii) Tendência a apoiar ou não a redistribuição; iii) Programas sociais; iv) Outras opiniões; v) Pobreza e desigualdade; vi) Princípio da igualdade; vii) Mobilidade social; e vii) Demografia e variáveis de auto-interesse.

O plano amostral e a condução das entrevistas ficaram sob responsabilidade da empresa contratada para o efeito. Em primeira instância foi realizado um teste piloto com a primeira versão do questionário -dois modelos diferentes foram aplicados no campo-, posteriormente foram feitas algumas mudanças considerando o desempenho das duas versões.

Segundo consta no relatório de campo, a amostra é representativa da população transeunte, maior de 16 anos. O cálculo da amostra foi realizado considerando as informações dos Censos Demográficos de 2000 e 2010 do IBGE. A pesquisa é do tipo ponto de passagem através da aplicação do questionário em forma pessoal. A estratificação da população corresponde às cinco regiões geográficas, é representativa das áreas urbanas e rurais com amostragem por conglomerados em três estágios: unidades de federação, municípios e pessoas.

As entrevistas foram realizadas em 48 pontos de passagem em 12 estados, em 36 munícipios sendo 12 capitais, 12 cidades das regióes metropolitanas e 12 de cidades do interior. 
A representatividade da amostra por região, sexo e idade foi garantida. O erro para a leitura geral dos dados é de 2,08 p.p., contudo, segundo manifesta a empresa contratada, as variáveis renda e educação não foram controladas pelas cotas e apresentam erros estimados importantes, propondo como solução a união de algumas categorias. No caso da renda, juntando as categorias a partir de 4.000 se tem um erro estimado de 5,6 p.p., no caso da educação juntando as categorias das pessoas que não têm ensino superior o erro é de 5,4 p.p., e no caso das pessoas que têm ensino superior o erro estimado é de 5,5 p.p. Neste trabalho foi adotada essa estratégia para trabalhar com essas variáveis. 